\title{
Review Article \\ Overview of Achievements and Challenges of the Fight against AIDS in China
}

\author{
Laiyi Kang \\ Shanghai Municipal Center for Disease Control and Prevention, 1380 Zhong Shan Xi Road, Shanghai 200336, China
}

Correspondence should be addressed to Laiyi Kang, lykang63@hotmail.com

Received 18 January 2012; Accepted 7 March 2012

Academic Editors: I. Mezzaroma, A. Taylor-Robinson, and A. Vyakarnam Copyright ( $) 2012$ Laiyi Kang. This is an open access article distributed under the Creative Commons Attribution License, which
permits unrestricted use, distribution, and reproduction in any medium, provided the original work is properly cited.

The epidemic of HIV/AIDS exists in China from more than 26 years and is still at a low prevalence $(<0.06 \%)$ on the global level. The purpose of this paper is to disclose the rational of how to keep the low rate through strenthening key strategies and comprehensive measures for prevention and control of the disease using collecting, reviewing, and analyzing surveillance data, special materials from publications, national meetings, symposiums, and forums, major research results as well as the personal experiences within the period of 1985-2011. In the meantime, the paper mentions that currently China is facing challenges and also going to carry out its actions concerning how to deal with the problems in order to respond to the UN CALL on "Getting to Zero".

\section{Introduction}

Just four years after the patients with AIDS were firstly reported in the world, the disease was also to transmit into China [1]. From June 1985 to October 2011, based on the notifiable report, system an accumulative number of HIV infections was up to 434459 in the country. However, the Chinese Ministry of Health working together with UNAIDS, $\mathrm{WHO}$, and relevant international organizations made an estimation of 780,000 alive PLHIV (people living with HIV) by the end of $2011[2,3]$.

The epidemic of HIV/AIDS has existed more than 26 years in China. It could be divided into three stages: the period of 1985-1988 was invasive stage, in which the HIV infections happened to foreign visitors and domestic people with foreign persons or using contaminated blood products from overseas; in 1989, 146 HIV infections were firstly identified among domestic IDUs in Rueli county of Yunnan province and then by the end of 1994 the occurrence of HIV was found in both domestic and foreign people, which was called the "growing up stage"; since 1995 the epidemic has been entering the "peak stage" when the epidemic was firstly discovered in the middle China due to cross-infection via plasmapheresis among paid blood donors. In the meantime, at the same year in first report on IDU outside Yunnan was found, and by the end of 1998 all provinces of the mainland have firstly reported HIV/AIDS. Now the epidemic is still at "peak stage" [4].

\section{Achievements of AIDS Control}

At present, China has stll been at a low prevalence epidemic of HIV/AIDS with $<0.06 \%$ in the global, which was reached at the goal of the National Plan for 11th Five year of less than number of 1,500,000 HIV infections. On the other hand, although the HIV epidemic is still going up every year, the speed of the epidemic has been slowing, that is, the new HIV infections were 70,000 in 2005, 50,000 in 2007, 48,000 in 2009 , and 48,000 in 2011, respectively. Especially, since 2004 antiretroviral therapy has conducted and graduated to increase the number of treated patients. The mortality of AIDS in China has been dropped down by $65 \%[5,6]$.

Why the updated incidence and prevalence of HIV in China is still low in the world?

2.1. Strenthening Leaderships and Laws Developments. HIV epidemic history of 30 years has already confirmed whether the achievement of the prevention and control of HIV/AIDS in any country and region depends on the government awareness and promise. Obviously, with great efforts China has integrated with all governmental departments, professional organizations, NGOs, and the public to fight against 
AIDS to keep the low prevalence of HIV. It should be pointed out that since the AIDS epidemic the Chinese government has strengthened the leadership, financial investment, and stipulation of relevant laws, regulations and policies. Especially, after SARS occurrence in 2003 the prevention and control of AIDS has been considered as one of the top diseases in China. In recent years in accordance with 9 priority measures developed by the United Nations the government has carried out and succeeded. Main actions can be briefly summarized, that is, strengthening governmental leadership at different levels; setting up AIDS Working Committee and executive offices under governments; putting AIDS issues in the official agenda; organizing mass units, civil society, and business enterprises to be trained and involved in the national and local response to AIDS; supporting the NGOs role; especial financial investment from governments, besides the local investment by which the central government has increased the financial budgets from 940 million RMB in 2007 to 2.4 billion RMB in 2010; stipulating relevant laws, regulations, and policies, especially continuing to protect the rights for HIV/AIDS infections and persisting on free charge of antiretroviral therapy. Currently, there are four particular laws to ensure the progress of the AIDS prevention and control tasks, which include "Law of National Prevention and Control of Infectious Diseases in the People's Republic of China" approved by the National People Delegation Congress, "Regulations on National Prevention and Control of AIDS" developed by the State Council, "Policy on Four Free One Care" promised by the People's Republic of China to the United Nations, and "Inform on Further Strengthening Work of Prevention and Control of AIDS" released by the State Council in the country. For example, the 3rd item of the regulation stated that any unit or any person is not allowed to discriminate people living with HIV, patients with AIDS, and their families. Their marriages, jobs, seeking medical doctors, school admission, and so forth, are protected by law. Thus, these laws and policies are absolutely to protect the work on AIDS prevention, treatment, and anti-stigma and to create a harmonious environment for the removal of discrimination [6-11].

2.2. Focusing on Professional Networks. surveillance network has been promoted, and HIV epidemic number has been reported much accurately. Besides the passive surveillance on the electronic report in all hospitals of the country, about 5,000 sites of national and local sentinel surveillance network among high-risk groups (MSM, FSW, long-distance drivers, etc.) and key populations (pregnant women, university students, etc.) have also been set up. For example, there were 1318 sentinel surveillance sites, including selected 14 groups and 465,295 persons, surveyed by the Central Sentinel Network in 2010. As a result, the rate of HIV antibody was $1.6 \%$. Average rates of HIV antibody among main groups were $5.6 \%$ in drug users, $8.0 \%$ in IDU, $0.4 \%$ in FSW, and $5.2 \%$ in MSM, respectively. In the meantime, there were 7335 clinics to serve Voluntary Counseling Testing (VCT) and 1,630,926 received counseling, of them 1,605,079 were tested for HIV antibody. Specifically, since 2005 the Ministry of Health in China cooperated with UNAIDS, WHO, US
CDC, and other international organizations to jointly release "Update on the HIV Epidemic and Response in China" every two years, from which according to the estimation of HIV/AIDS the cumulative number of PLHIV was 650,000 in $2005,700,000$ in 2007, 740,000 in 2009, and 780,000 in 2011, respectively [12-19].

\subsection{Health Promotion and Intervention. Measures for AIDS} prevention and control have continued to be strengthened. Besides the health education, professional organizations have been further completed, such as the central and local CDC system, designated hospitals and maternal-infant institutes not only were set up nationwide but also serviced for AIDS prevention, intervention, and clinical care more better efficiently; more than 9,000 HIV labs (including screening and confirmatory labs) are responsible for diagnosis, monitoring, evaluation, research, and technical support. Management of blood donation and clinical use has been strengthened. Such a kind of HIV epidemic due to cross-infection by plasmapheresis has never been found since 1995. Comprehensive intervention for high-risk groups (including MSM, FSW, and PLHIV) has been conducted by different levels of local intervention teams in provinces to reduce HIV/STI transmission in communities, in which the promotion of condom use and methadone maintenance treatment clinics (MMTC) have been carried out as priority measures and also succeeded. For example, based on sentinel surveillance data in 2009 the rates of condom use calculated from their last intercourse were up to $85.1 \%$ among FSW and $73.1 \%$ among MSM, respectively. In the same year, there were 680 methadone maintenance treatment clinics in the country, in which 241,975 people with IDU were treated to estimate reduction of 3000 people with new HIV infection and reduction of heroin consumption to be 22.4 tons; more than 1.4 million pregnant women were screened for HIV antibody among several provinces with higher HIV prevalence, and interruption rate of maternal-infant transmission was $75.3 \%$ [20-22].

2.4. National Campaign on Free Anti-Retroviral Therapy. As requested by the national policy of "Four Free, One Care" free AIDS treatment program has been carried out since 2004. Up to now a total number of 140,000 patients with AIDS have received HAART, and of them 110,000 patients can persist on the treatment in 2011, whose coverage has reached $80 \%$. Additionally, 14,344 patients with AIDS have been treated by the second line of ART due to serious side effects and drug resistance. Absolutely, the observational data showed the enhancement of their living quality and reduction of their mortality. It was evident that the survival rate increased after ART and the rate after 12-month treatment was on average $83.6 \%$ in 2009 . The case mortality rates for adults with AIDS were 28/100 person-year and 5/100 person-year before and after ART, respectively [23-28].

2.5. Development of National HIV Molecular and HIV Drug Resistance Researches. Since 1995 China CDC and 31 provincial CDC have been developed HIV network for molecular 
epidemiology surveillance and from 2004 the HIV Drug Resistance (HIVDR) Surveillance and Monitoring Network has been developed, in which four state key labs became national level of the network and one of them, which is located in China CDC, was appointed as Regional HIVDR Lab by WHO. Two nationwide HIV molecular epidemiological surveys were conducted in China. The first one was conducted in the 90s (1996-1998) of the last century. As a result, HIV-1 B' subtype was predominant (47\%); CRF-BC was next $(30 \%)$. However, the findings from the second survey in the first decade (2001-2003) of the 21st Century showed that the distribution of HIV-1 subtypes has changed and subtype diversity has occurred, revealing a distinctively geographic distribution of subtypes in China and diverse subtypes circulating in China. Subtype B' (Thai-B) is dominating in the central part of China (Henan, Hubei, Anhui, Shanxi, etc.), and CRF07_BC is dominating in northwest (Xinjiang), and southwest (Chongqing) as well. CRF08_BC is dominating in the southeast/south (Guangxi and Yunnan, etc.), while CRF01_AE is dominating in the coastline provinces, such Shanghai, Zhejiang, Jiangsu, and Shandong, besides Guangxi and Yunnan. With the spreading of HIV-1 through sexual contact (including MSM), CRF01_AE is spreading in most of the provinces of China. China is now becoming one of the countries where multiple HIV-1 subtype strains exist. In 2001-2003, at least 6 subtypes, B', B, A, C, CRF07/08 and CRF01_AE, existed. Of them, 50\% were CRF_BC, if plus CFR_AE (15\%), near two-third of the subtypes being recombinant. An analysis of subtypes by transmission mode presented that except for blood donor' subtypes identified mostly as B', the results from two surveys were quite different. For example, among drug users in the last century, $91 \%$ were infected with B' and/or C strains, while in the 21st Century, 81\% and 18\% were CRF07/08_BC and CRF01_AE strains, respectively. Subtype B' and C strains were rarely seen. Sex transmission is now a leading cause of spreading different subtypes in China. In the survey of the last century, CRF01_AE (67\%) was mainly detected in persons who identified as sexual contact, while in the 21st century, the subtypes were identified as CRF07/08_BC (30\%), CRF01_AE (27\%), B' (25\%), and C, A, and CRF02_AG (16\%). Although the national-level survey has not been carried out in recent years, several provinces have independently conducted the investigation of HIV-1 genetic subtypes. Actually, diverse HIV-1 subtypes have been found in different provinces over the past years. Most of HIV-1 clades and some unique recombination form (URF) strains have so far been identified in China [29-38].

As is well known, development and transmission of HIV drug resistance (HIVDR) has become the barrier of the use and promotion of highly active antiretroviral therapy (HAART) and therefore has become a public concern. China is one of the resource-limited countries. Surveillance of transmitted HIV drug resistance (TDR) is an essential public health component of a comprehensive HIV strategy. Since 2004 according to the WHO recommendation, China has conducted several surveillances. In addition to periodical HIVDR retrospective and perspective surveys among treatment-naïve and ARV-treated patients, the key surveys include HIVDR early warning indicators, HIVDR sentinel surveillance, and HIVDR threshold survey. At present, although the rate, TDR has, and is increased by year it is still relatively low in China. For example, TDR rates of $2.9 \%$ in $2004,4.4 \%$ in 2005 , and $3.6 \%$ in 2009 , were still lower as compared with other countries. On the other hand, randomized investigation of HIVDR among patients with HAART treatment has been carried in certain out provinces annually, that is, 14 provinces in 2004,31 provinces in 2005 , 28 provinces in 2006 2007, and 10 provinces in 2009 2010 [30]. As a result, there was an obvious difference in HIVDR rates by different medication protocols for the first-line therapy. The rate of HIVDR using AZT/DDI/NVP and D4T/DDI/NVP was up to $25.7 \%$, while the HIVDR rate using modified first-line protocols (AZT/3TC/NVP, $\mathrm{D} 4 \mathrm{~T} / 3 \mathrm{TC} / \mathrm{NVP}$, or AZT/3TC/EFV and D4T/3TC/EFV) was only $1.6-9.1 \%$. Unfortunately, the updated rate of HIV mutation among patients with the first-line ARV therapy in some areas was up to $30 \%$, which gave the evidence to use the second-line ARV therapy, instead. Comparison of HIVDR rate in 3 major ART groups revealed that higher HIVDR rates were associated with non-nucleoside reverse transcriptase inhibitors (NNRTIs) and with nucleoside reverse transcriptase inhibitors (NRTIs), while HIVDR rate associated with protease inhibitors was much lower. Specifically, at present the average rate of HIV-1 drug resistance has been 9.5\% in the whole country in 2009-2010, which was much lower than the rate of $17.8 \%$ within the period of 2006-2007 due to taking 3TC in place of DDI for the first-line therapy. The most frequent NRTI or NNRTI-related mutations were $\mathrm{M} 184 \mathrm{~V} / \mathrm{I}$ and $\mathrm{K} 103 \mathrm{~N} / \mathrm{R}$, respectively. Within the period of 2008-2009, a nationwide survey focusing on HIV infection among MSM from 61 cities was conducted and it revealed that the average rate for HIV infection in this population was $5 \%$, some being more than $10 \% .363 \mathrm{HIV}$ strains from MSMs living in 15 provinces were detected, and the average HIVDR was $6.1 \%$ (including 3 provinces $>10 \%$ ). It is noteworthy that the primary HIVDR rate was much higher than in other populations $(<5 \%)$. The most frequent mutation codon detected in HIV-1-infected MSM was V118I. It should be pointed out that although from 2004 to now the strategies for HIVDR surveillance and monitoring have been conducted for the purpose of public health surveillance in China, since 2010 the Ministry of Health has required a genotyping detection of one-tenth of ARV treatment individuals in order to understand if the clinical failure has occurred due to the drug resistance using the first-line therapy and determine if it is necessary to use the second-line ARV therapy instead of the first-line therapy. The integration of the HIVDR public health surveillance and individual clinical HIVDR testing is a new attempt in China [39-49].

2.6. Reinforcing Scientific Research and International Collaborations. Scientific research projects and collaborations have been heightened. In order to enhance the quality of HIV prevention and control, reduce the incidence rate of new infections and to create new high technology, the Chinese government has paid much more attention to scientific and technological research. Over the lasttwo years, 
a total of $316,180,000 \mathrm{RMB}$ were funded to national mega research programs focusing on the novel HIV diagnostic reagents, epidemic patterns, ART treatment, HIVDR surveillance, immune protection mechanism, biological prevention intervention, vaccine development, HIV and research on $\mathrm{TB} / \mathrm{HBV} / \mathrm{HCV}$ coinfections, and so forth. In the meantime, international and domestic collaborations have become key ways to learn different countries and areas knowledge and experience in HIV/AIDS field through the Global Foundation, China-US, China-Canada projects, and so forth, to promote effective work on AIDS control [50].

\section{Challenges and Further Actions}

Although the HIV epidemic in China is still low, Chinese people are now facing different challenges, that is, lack of AIDS knowledge among the public, even among medical staff; wide existence of HIV epidemic factors, including MSM, FSW, and IDU having multiple sex behavior, low rate of persisting condom use, a certain rate for sharing needle and syringes, and increase in new abuse drugs, especially health promotion and intervention among those high risk people not easily to access and persist on; high population movement of 220 million annually from countryside to cities; about half of the estimated alive people with HIV/AIDS not to be identified and to find new infected people the difficulty, while one-fourth of the current patient are already at clinical stage when just diagnosing; stigma and discrimination in the society seriously, especially from medical staff; emergent increase in HIV drug resistance; heavy responsibility for HIV vaccine, curable anti-HIV drugs, and new diagnostic method development; weak system of monitoring and evaluation; some local leaderships lack of awareness and promise, lack of professional personnel and teams, and also lack of experience and resources for promoting TasP and PrEP programs.

On September 12, 2011 the United Nations has called on "Getting to Zero" for AIDS on the global level, that is, in 2020, there would be "No New HIV Infection, No Discrimination and No AIDS-Related Death". The Chinese are to observe the promise. How to deal with the above challenges? Besides the government should continue to strengthen leaderships, further carry out the responsibilities at work, recently a special policy, entitled "An Inform on further strengthening AIDS prevention and Control in the country" has been stipulated by the State Council, in which the contents can be briefly summarized as "Five Expanding, Six Strengthening". "Five Expending" refers to expand coverage rates of propaganda and education, surveillance and testing, prevention of maternal-infant transmission, comprehensive intervention, and antiretroviral treatment; "Five Strengthening" refers to strengthen blood management, medical safeguard, care and aids, right protection, organization and leadership, team construction of prevention and control, and international collaborations. From now, the Chinese people, especially public health doctors and medical personnel, are following the policy to welcome the future by stopping the HIV epidemic [51-62]. We are confident that along with the above actions China can continue to keep the low rates of the incidence and prevalence in the world.

\section{References}

[1] L. Y. Kang, "Threatened by the high-risk factors," AIDS Analysis, vol. 1, no. 1, article 16, 1995.

[2] Ministry of Health, People's Republic of China Joint United Nations Programme on HIV/AIDS and World Health Organization, "Estimates for the HIV/AIDS epidemic in China. National Center for AIDS/STD Control and Prevention," CDC, Beijing, China, May 2010.

[3] CDC and Ministry of Health, People's Republic of China Joint United Nations Programme on HIV/AIDS and World Health Organization, "Estimates for the HIV/AIDS epidemic in China. ," National Center for AIDS/STD Control and Prevention, CDC, Zhejiang, China, 2011, http://www.chinaids.org .cn/n1971/n2151/777994.html.

[4] L. Y. Kang and X. Z. Pan, Prevention and Treatment of AIDS, Fu Dan University Press, 2008.

[5] B. A. Kohler, E. Ward, B. J. McCarthy et al., "Annual report to the nation on the status of cancer, 1975-2007, featuring tumors of the brain and other nervous system," Journal of the National Cancer Institute, vol. 103, no. 9, pp. 714-736, 2011.

[6] State Council, Regulation on Prevention and Control of AIDS, China Legal System Press, 2006.

[7] The 93rd Order from the President of the People's Republic of China, "Law of Blood Donation of the People's Republic of China," in Proceedings of the 8th National People Representative Congress, China Legal System Press, December 1997.

[8] Ministry of Health, People's Republic of China, Regulation on National Working Management of AIDS Testing, China Legal System Press, 2006.

[9] L. Y. Kang, "Objectives and significance of stipulation for "Regulation on National Management of HIV Laboratory Testing" ," Chinese Journal of Laboratory Medicine, vol. 31, no. 10, pp. 1091-1094, 2008.

[10] Y. M. Shao, L. Y. Kang, N. Wang et al., "Health Industry Criteria of the People's Republic of China: Diagnosis Criteria for AIDS and HIV infection," The Ministry of Health, the People's Republic of China, 2007.

[11] The State Council, "Decision on Revising "Implementation Regulations on the People's Republic of China Law of Border Health Quarantine"'” April 2010, http://www.chinaaid.org/.

[12] M. Jia, H. Luo, Y. Ma et al., "The HIV epidemic in Yunnan province, China, 1989-2007," Journal of Acquired Immune Deficiency Syndromes, vol. 53, no. 1, supplement, pp. S34-S40, 2010.

[13] Y. Xiao, J. Sun, C. Li et al., "Prevalence and correlates of HIV and syphilis infections among men who have sex with men in seven Provinces in China with historically low HIV prevalence," Journal of Acquired Immune Deficiency Syndromes, vol. 53, no. 1, supplement, pp. S66-S73, 2010.

[14] N. Li, Z. Wang, D. Sun et al., "HIV among plasma donors and other high-risk groups in Henan, China," Journal of Acquired Immune Deficiency Syndromes, vol. 53, no. 1, supplement, pp. S41-S47, 2010.

[15] Y. Li, R. Detels, P. Lin et al., "Prevalence of HIV and STIs and associated risk factors among female sex workers in guangdong Province, China," Journal of Acquired Immune Deficiency Syndromes, vol. 53, no. 1, supplement, pp. S48-S53, 2010.

[16] L. Wang, W. Liu, L. Wang, Y. Wang, and Z. Wu, "HIV prevalence among pulmonary tuberculosis patients in Guangxi, 
China," Journal of Acquired Immune Deficiency Syndromes, vol. 53, no. 1, pp. S61-S65, 2010.

[17] R. S. Remis, L. Y. Kang, Q. C. Pan et al., "Prevalence of HIV infection and STI among female entertainment workers (FEWs) in Shanghai, China," in Proceedings of the 18th International AIDS Conference (AIDS '10), Vienna, Austria, July 2010.

[18] H. Zou, Z. Wu, J. Yu et al., "Sexual risk behaviors and HIV infection among men who have sex with men who use the internet in Beijing and Urumqi, China," Journal of Acquired Immune Deficiency Syndromes, vol. 53, no. 1, supplement, pp. S81-S87, 2010.

[19] Y. Feng, Z. Wu, and R. Detels, "Evolution of men who have sex with men community and experienced stigma among men who have sex with men in Chengdu, China," Journal of Acquired Immune Deficiency Syndromes, vol. 53, no. 1, supplement, pp. S98-S103, 2010.

[20] Ministry of Health of the People's Republic of China, "UNGASS Country Progress Report, China, 2010," Printed by the State Council AIDS Working Committee Office, April 2010.

[21] State Council AIDS Working Committee Office and UN theme Group on AIDS in China, "A Joint Assessment of HIV/AIDS Prevention, Treatment and Care in China," State Council AIDS Working Committee Office, December 2007.

[22] Ministry of Health, People's Republic of China, Joint United Nations Programme on HIV/AIDS, World Health Organization, "Update on the HIV/AIDS Epidemic and Response in China," National Center for AIDS/STD Prevention and Control, China CDC, Beijing, China, January 2006.

[23] F. J. Zhang, "Progress on Anti-retroviral therapy in China," Speech at National Free Charge of ART and HIV drug resistance in clinic, Beijing, China, December 2011.

[24] W. S. Guo, Q. H. Hu, M. Zhang, W. G. Cui, and H. Li, "Survey of anti-HIV treatment for HIV infections and development of drug resistance in Henan province," Chinese Journal of AIDS \& STD, vol. 12, no. 4, pp. 304-306, 2006.

[25] Y.-M. Shao and L.-Y. Kang, "Some suggestions on Strengthening the clinical work of AIDS in China," Journal for China AIDS/STD Prevention and Control, vol. 6, no. 6, p. 382, 2000.

[26] L. Y. Kang and X. Z. Pan, "Development and application of antiretroviral therapy for Required Immunodeficiency Syndrome," Chinese Journal of Infectious Diseases, vol. 20, pp. 133-136, 2002.

[27] F. J. Zhang, J. Pan, and L. Yu, "Current progress of China's free ART program," Cell Research, vol. 15, pp. 877-882, 2005.

[28] The Editor Group, National Textbook on Antiretroviral Drug Therapy in Free of Charge, People's Health Publishing, Beijing, China, 2nd edition, 2008.

[29] Y. Shao, "AIDS epidemic at age 25 and control efforts in China," Retrovirology, vol. 3, p. 87, 2006.

[30] X. Han, D. Dai, B. Zhao et al., "Genetic and epidemiologic characterization of HIV-1 infection in liaoning province, China," Journal of Acquired Immune Deficiency Syndromes, vol. 53, no. 1, supplement, pp. S27-S33, 2010.

[31] J. R. Yi, H. Y. Loo, and L. S. Bai, "Characteristic Study on epidemic HIV-1 strain of CRF01_AE subtype in Beijing," Chinese Journal of Epidemiology, vol. 31, no. 11, pp. 12311234, 2010.

[32] L. Li, S. Liang, L. Chen et al., "Genetic characterization of 13 subtype CRF01-AE near full-length genomes in Guangxi, China," AIDS Research and Human Retroviruses, vol. 26, no. 6, pp. 699-704, 2010.
[33] W. Deng, P. Fu, L. Bao et al., "Molecular epidemiological tracing of HIV-1 outbreaks in Hainan island of southern China," AIDS, vol. 23, no. 8, pp. 977-985, 2009.

[34] P. Zhong, Q. Pan, Z. Ning et al., "Genetic diversity and drug resistance of human immunodeficiency virus type 1 (HIV-1) strains circulating in Shanghai," AIDS Research and Human Retroviruses, vol. 23, no. 7, pp. 847-856, 2007.

[35] H. Guo, D. Guo, J. F. Wei et al., "First detection of a novel HIV type 1 CRF01-AE/07-BC recombinant among an epidemiologically linked cohort of IDUs in jiangsu, China," AIDS Research and Human Retroviruses, vol. 25, no. 4, pp. 463467, 2009.

[36] P. Zhong, Q. Pan, Z. Ning et al., "Genetic diversity and drug resistance of human immunodeficiency virus type 1 (HIV-1) strains circulating in Shanghai," AIDS Research and Human Retroviruses, vol. 23, no. 7, pp. 847-856, 2007.

[37] P. Zhong, L. Kang, Q. Pan et al., "Identification and distribution of HIV type 1 genetic diversity and protease inhibitor resistance-associated mutations in Shanghai, P. R. China," Journal of Acquired Immune Deficiency Syndromes, vol. 34, no. 1, pp. 91-101, 2003.

[38] J. R. Ye and Y. Zeng, "Progress of study on HIV subtype inChina, 2000-2010," unpublished.

[39] Y. M. Shao, J. Y. Li, L.Y. Kang, H. Shang, P. Zhong, and H. Xing, Book on the Strategy and Methodology for HIV Drug Resistance Surveillance and Detection, People's Medical Publishing House, 2010.

[40] L. Liao, H. Xing, H. Shang et al., "The prevalence of transmitted antiretroviral drug resistance in treatment-naive HIVinfected individuals in China," Journal of Acquired Immune Deficiency Syndromes, vol. 53, no. 1, supplement, pp. S10-S14, 2010.

[41] J. Y. Choi, E. J. Kim, Y. K. Park, J. S. Lee, and S. S. Kim, "National survey for drug-resistant variants in newly diagnosed antiretroviral drug-naive patients with HIV/AIDS in South Korea: 1999-2005," Journal of Acquired Immune Deficiency Syndromes, vol. 49, no. 3, pp. 237-242, 2008.

[42] N. Vidal, C. Mulanga, S. E. Bazepeo et al., "HIV type 1 pol gene diversity and antiretroviral drug resistance mutations in the Democratic Republic of Congo (DRC)," AIDS Research and Human Retroviruses, vol. 22, no. 2, pp. 202-206, 2006.

[43] Chinese HIV Drug resistance Research Group, "Public Health Surveillance on HIV-1 drug resistance from 2004 to 2010 in China," In press.

[44] Y. Han, J. Q. Kuang, T. S. Li et al., "Surveillance on primary genotyping drug resistance among 237 naïve-patients with HIV/AIDS and analysis of HIV subtypes in China," Chinese Journal of Laboratory Medicine, vol. 31, no. 10, pp. 1095-1100, 2008.

[45] L. G. Feng, H. J. M. Wang, M. Han, X. B. Dian, and Y. Jiang, "Surveillance on HIV drug resistance for recently acute infection among MSM who have sex with men in Zhongqing," Chinese Journal of Epidemiology, vol. 29, no. 5, pp. 455-458, 2008.

[46] H. Tan, F. G. Zhan, W. P. Chen, D. H. Peng, Y. Dai, and X. G. Zhu, "Analysis of drug resistance surveillance among AntiHIV treatment individuals in Hubei province," Public Health and Preventive Medicine, vol. 18, no. 5, pp. 26-28, 2007.

[47] X. B. Zhu, J. M. He, G. Q. Zhang, X. Z. Li, J. Y. Peng, and X. Chen, "Analysis of drug resistance among patients after ART in Hunan province," Chinese Journal of AIDS \& STD, vol. 9, no. 5, pp. 305-309, 2010.

[48] China CDC, Working Plan for HIV Drug Resistance in 2010, Office of China CDC, 2010. 
[49] L. Y. Kang, "Development and application of HIV testing technologies for HIV/AIDS highly active anti-retroviral therapy in China," Chinese Journal of Laboratory Medicine, vol. 32, no. 4, pp. 365-368, 2009.

[50] The Ministry of Science and Technology, People's Republic of China, "National "Eleventh Five-Years" Science and Technology Development Plan-Prevention and Control of AIDS, Viral Hepatitis, etc.", March 2011, http://most.gov.cn/.

[51] The State Council, "Information of Further Strengthening Work on Prevention and Control of AIDS," February 2011, http://www.chinaaids.org/.

[52] The Office of Ministry of Health, "Information on Carrying out Protocol of the Work on Prevention of AIDS, Syphilis and HBV Maternal Infant Transmission," February 2011, http://www.chinaaids.org/.

[53] Z. Wu and Y. Wang, "Introduction: China meets new AIDS challenges," Journal of Acquired Immune Deficiency Syndromes, vol. 53, no. 1, supplement, pp. S1-S3, 2010.

[54] L. Y. Kang, "It's necessary to educate and promote of condom use as an important intervention to interrupt of HIV/STD transmission," China Journal of Prevention and Control of STD/ AIDS, vol. 2, no. 6, p. 282, 1996.

[55] K. Lai-Yi, F. Hui, J. Zhi-Chen et al., "A feasibility study on condom use in a hotel," Chinese Journal of Epidemiology, vol. 3, no. 13, p. 100, 1995.

[56] Y. C. Wang, C. D. Zhang, S. B. Xu, H. Z. Yi et al., HIV Laboratory Testing Technique and Quality Assurance, Science Publishing, Beijing, China, 2009.

[57] Y. Jiang, N. Wang, W. G. Xing, Y. Xiao, J. Yao, P. L. Pan et al., Book on Development of a Network of AIDS Laboratory for 20 Years in China, Beijing Science and Technology Publishing, Beijing, China, 2009.

[58] Z. Zhou, K. Meyers, X. Li et al., "Prevention of mother-tochild transmission of HIV-1 using highly active antiretroviral therapy in rural Yunnan, China," Journal of Acquired Immune Deficiency Syndromes, vol. 53, no. 1, supplement, pp. S15-S22, 2010.

[59] F. Zhang, J. E. Haberer, Y. Wang et al., "The Chinese free antiretroviral treatment program: challenges and responses," AIDS, vol. 21, no. 8, supplement, pp. S143-S148, 2007.

[60] L. Xiao, Z. Wu, W. Luo, and X. Wei, "Quality of life of outpatients in methadone maintenance treatment clinics," Journal of Acquired Immune Deficiency Syndromes, vol. 53, no. 1, supplement, pp. S116-S120, 2010.

[61] The Office of Ministry of Health, "Information on Carrying out Protocol of the Work on Prevention of AIDS, Syphilis and HBV Maternal Infant Transmission,” February 2011, http://www.chinaaids.org/.

[62] Ministry of Health, "Carrying Out Regulations on Management Rules in Public Places (The No. 80 Order from the Ministry of Health)," March 2011, http://www.chinaaids.org/. 


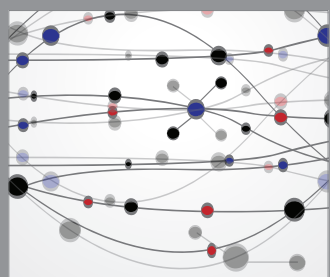

The Scientific World Journal
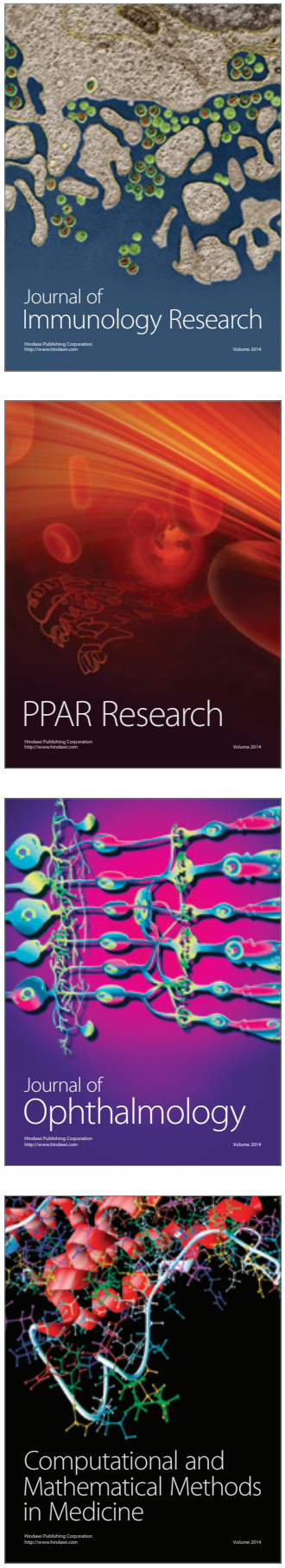

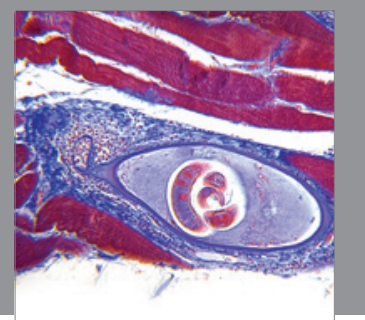

Gastroenterology

Research and Practice
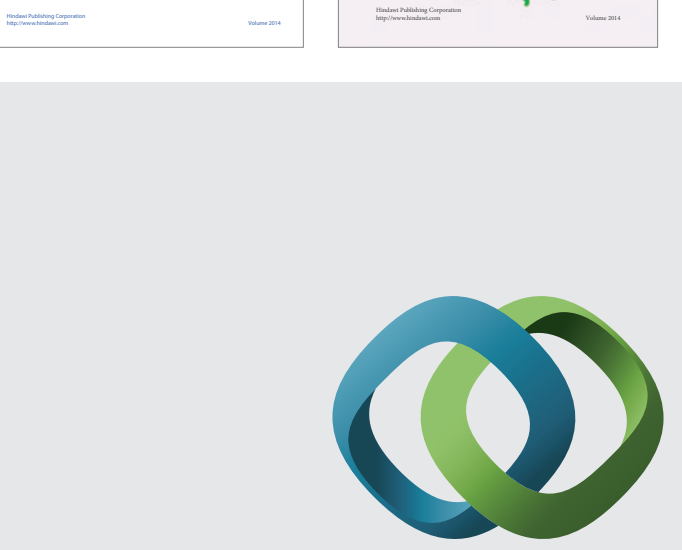

\section{Hindawi}

Submit your manuscripts at

http://www.hindawi.com
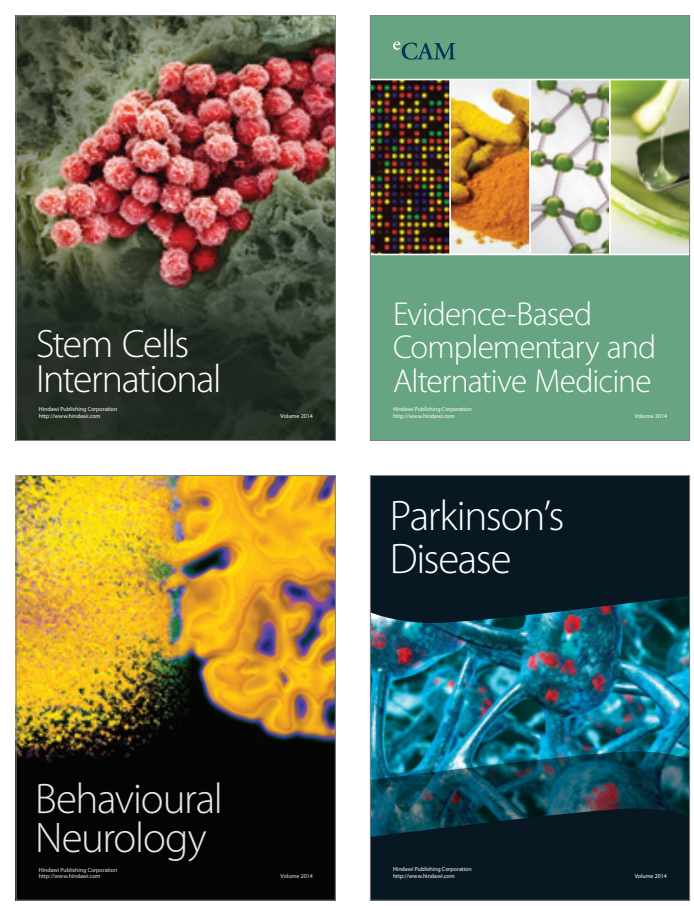

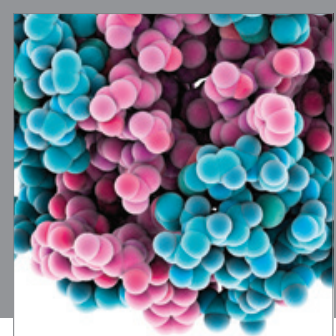

Journal of
Diabetes Research

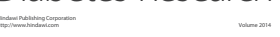

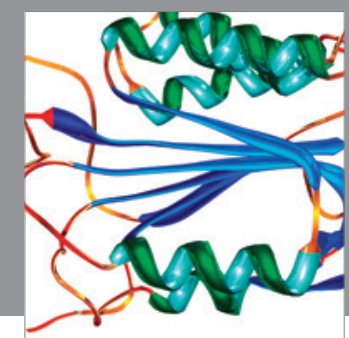

Disease Markers
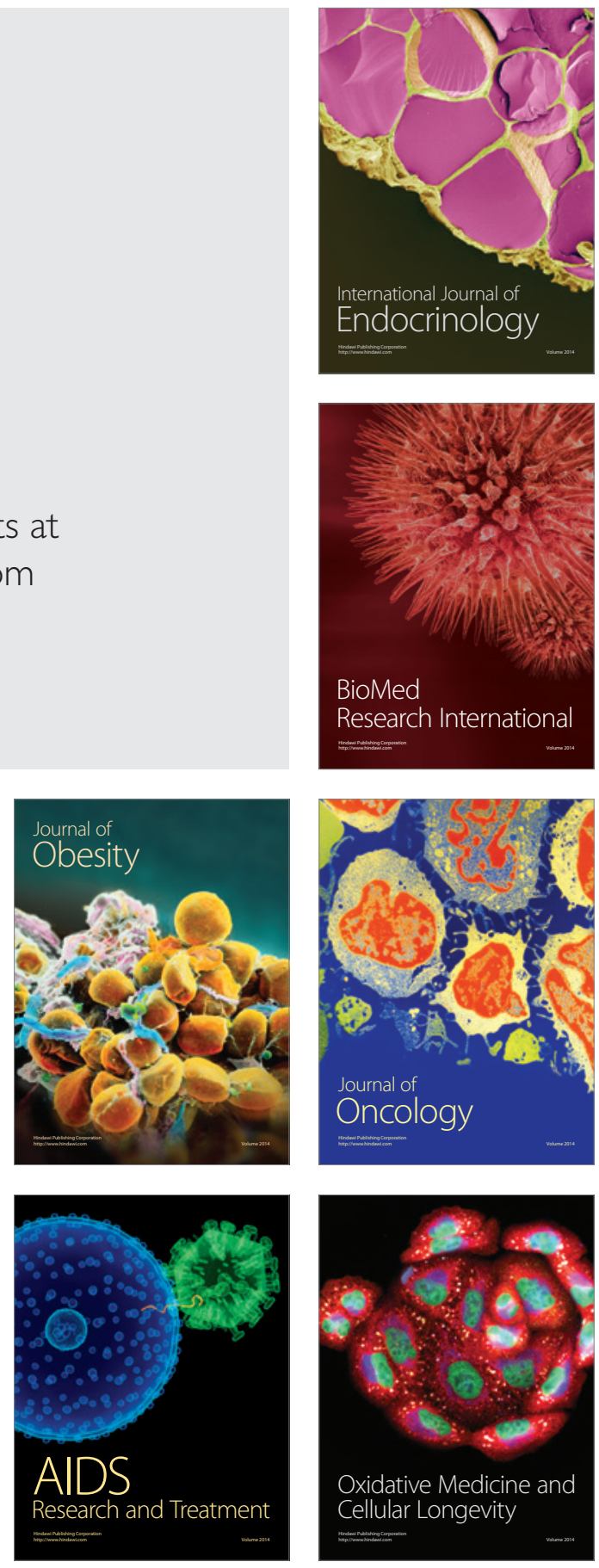